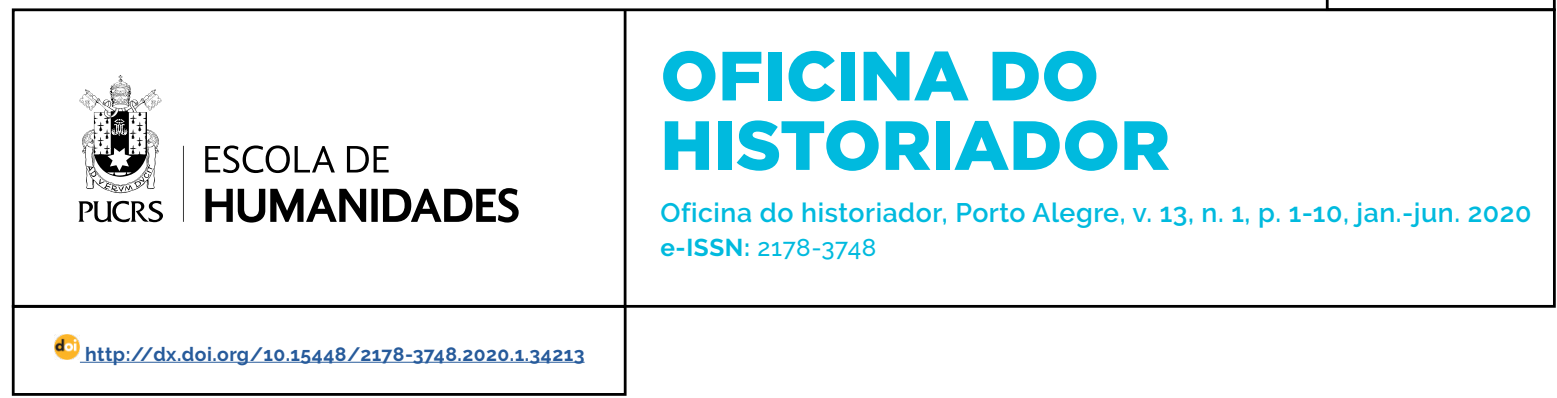

SEÇÃO: ARTIGOS

\title{
A contestação sobre rodas: Passo Fundo, os "agitadores" e a revolta dos motoqueiros no contexto da abertura política da ditadura militar
}

The contestation on wheels: Passo Fundo, the "agitators" and the bikers revolt in the context of the military dictatorship political opening

\author{
Alex Antônio Vanin ${ }^{1}$ \\ orcid.org/0000-0001-5617-2933 \\ alexvanin@hotmail.com
}

\section{Roberto Biluczyk ${ }^{1}$}

orcid.org/0000-0003-2429-8748

104666@upf.br

Recebido em: 20 mai. 2019. Aprovado em: 16 dez. 2019. Publicado em: 14 jun. 2020.

\section{(c) (i)}

Artigo está licenciado sob forma de uma licença Creative Commons Atribuição 4.0 Internacional.
Resumo: O presente trabalho objetiva tratar sobre como se deu a vigilância exercida pelo regime militar em Passo Fundo, RS, durante o mês de fevereiro de 1979, através do Serviço Nacional de Informações (SNI), organismo de fiscalização e supervisão criado em 1964. Busca-se analisar os antecedentes e desdobramentos do evento que ficou conhecido popularmente como Revolta dos Motoqueiros, organizado em protesto pela morte de Clodoaldo Teixeira, jovem de 17 anos baleado nas costas por um policial militar, após uma perseguição. O SNI produziu processos em torno desse caso, apresentado como "perturbação da ordem pública", identificando e vigiando os supostos agitadores da revolta. Nesse sentido, o acompanhamento do órgão federal sobre a situação é paradigmático para Passo Fundo no periodo, resultante do questionamento aos poderes instituidos e suas formas de ação em pleno regime de exceção. A documentação analisada possuía estatuto de confidencial no passado, mas hoje está disponivel livremente no site do Arquivo Nacional.

Palavras-chave: Passo Fundo. Serviço Nacional de Informações. Revolta dos Motoqueiros.

Abstract: This article aims to deal with how the military regime's surveillance in Passo Fundo / RS took place during February 1979, through the Servico Nacional de Informações (SNI), a public spy agency created in 1964. It also seeks to analyze the background and developments of the event popularly known as the Revolta dos Motoqueiros, organized in protest over the death of Clodoaldo Teixeira, 17 years old, shot in the back by a military policeman after a persecution. The SNI produced processes around this case, presented as a "disturbance of public order", identifying and overseeing the alleged agitators of the revolt. In this sense, the monitoring of the federal agency on the situation is paradigmatic for Passo Fundo in the period, resulting from questioning the instituted powers and their forms of action in full regime of exception. The reviewed documentation had confidential status in the past, but is now freely available on the Arquivo Nacional website. Keywords: Passo Fundo. Serviço Nacional de Informações. Bikers Revolt.

\section{Introdução}

O presente artigo visa analisar a vigilância estabelecida pelo Serviço Nacional de Informações (SNI) em Passo Fundo durante um evento de contestação às autoridades militares ocorrido em fevereiro de 1979, conhecido localmente como Revolta dos Motoqueiros. Busca-se, através desta pesquisa, compreender de que forma estes eventos foram acompanhados e vigiados pelo órgão, quem foi considerado responsável 
pela deflagração e incitação dos atos e que papel estas pessoas desempenharam nesses eventos.

Para tanto, através de uma análise qualitativa das fontes, serão utilizados os processos de investigação e recolhimento de informações arquivados no fundo Serviço Nacional de Informações (SNI), disponivel para consulta no Sistema de Informações do Arquivo Nacional (SIAN), sobretudo aqueles que versam sobre os eventos ocorridos e os envolvidos na revolta.

Esses processos se encontram atualmente em livre acesso ${ }^{2}$, agregando uma variada gama de documentos sobre a ditadura militar ${ }^{3}$. mostrando-se como uma fonte inédita para o desenvolvimento de novas pesquisas históricas relativas ao periodo, uma vez que muitos desses fundos eram considerados confidenciais no passado. Para o embasamento teórico, além das produções sobre o período ditatorial brasileiro, serão utilizadas obras de autores passo-fundenses que abordaram a questão dos acontecimentos descerrados em fevereiro de 1979.

\section{A "perturbação da ordem pública" em Passo Fundo}

Conforme o jornal passo-fundense O Nacional, no final da tarde do dia 5 de fevereiro de 1979, o jovem Clodoaldo Teixeira, de 17 anos, que atuava profissionalmente em uma oficina mecânica da área central da cidade de Passo Fundo, RS, dirigia-se para sua casa após o fim do expediente, em sua motocicleta. Ainda no Centro, foi barrado por uma patrulha da Brigada Militar (BM)4, para a qual não parou, pondo-se em fuga a fim de despistá-la, uma vez que não possuía carteira de habilitação, em função de sua menoridade.

A perseguição policial ao rapaz teve início com os patrulheiros o seguindo em alta velocidade até sua casa, na Vila Annes. Já próximo de sua residência, Clodoaldo foi atingido pelas costas por um disparo de arma de fogo efetuado por um dos policiais. A vítima foi socorrida por seu pai, Nelson Teixeira, enquanto, segundo a reportagem de $O$ Nacional, os policiais se afastavam rapidamente do local. Clodoaldo faleceu antes mesmo de receber atendimento médico no Hospital da Cidade (TIRO..., 1979, p. 1).

A narrativa do jornal O Nacional assumia tons de aberta denúncia dos fatos ocorridos, destacando e nomeando atores envolvidos naquela ocorrência policial. A patrulha da BM era constituida pelos policiais militares Clóvis Amaral Raiter e Jacinto Xavier Chaves e pelo cabo José Valmor da Silva, tendo esse último efetuado o disparo que vitimou fatalmente Clodoaldo. O motivo da perseguição policial teria sido o excesso de velocidade do jovem e de outros motoqueiros naquele dia. Contudo, apenas Clodoaldo foi perseguido e baleado.

Segundo Almeida (2006), notícias correram pela cidade ainda na noite e madrugada daquele dia, repercutindo em razão da brutalidade do ato policial, bem como pela indignação causada na população em geral pelo mesmo. A comoção se fez sentir ainda maior no dia posterior, quando do velório de Clodoaldo, realizado em sua casa e, posteriormente, com seu enterro, no Cemitério do Bairro Petrópolis, que, de acordo com o Nacional, chegou a reunir milhares de pessoas, de forma que comoção parecida só havia sido vista, "em 1954 quando morreu Getúlio Vargas" (COMOÇÃO..., 1979, p. 2).

Os manifestos se deram principalmente por meio de integrantes do Passo Fundo Moto Clube, amigos da vítima, uma vez que Clodoaldo foi morto na condição de motociclista. Dada a proeminência da imagem destas pessoas, os atos de protesto ficaram conhecidos como Revolta dos Motoqueiros, denominação posteriormente atribuida aos fatos ocorridos.

As manifestações em torno do caso, na cidade, logo tornar-se-iam alvo da vigilância e intervenção governamental. De acordo com documentação

\footnotetext{
2 Ver mais no site do Arquivo Nacional, disponivel em: http://www.arquivonacional.gov.br. Acesso em: 1 fev. 2019.

Neste artigo, optou-se pelo emprego do termo ditadura militar, para se referir ao regime de exceção implantado no Brasil entre 1964 e 1985. Há, conforme o historiador Demian Bezerra de Melo (2012), desde o decorrer dos anos 2000, uma tendência de alguns historiadores em denominar o periodo como "ditadura civil-militar", como forma de enfatizar a participação de civis no processo. Melo (2012) acredita que o uso do termo está deslocado em sua concepção original, proposta por René Armand Dreifuss, uma vez que superestima o papel dos "civis" frente ao comando do País exercido por militares, distribuindo culpas em uma tentativa de revisionismo histórico.

4 Instituição equivalente no Rio Grande do Sul à Polícia Militar no resto do Brasil.
} 
gerada pelo Serviço Nacional de Informações (SNI), por meio da Agência de Porto Alegre (APA), instalava-se naquele fevereiro de 1979 em Passo Fundo um caso de "perturbação da ordem pública".

O SNI foi um órgão federal criado pelo ditador Humberto de Alencar Castello Branco em 13 de junho de 1964, vinculado diretamente à Presidência da República, que objetivava "superintender e coordenar nacionalmente as atividades de informação e de contrainformação" (KORNIS, 2009), corroborando com a fiscalização da segurança nacional no período. Desenvolvido com propósitos mais modestos dos que adquiriria a partir de março de 1967, o SNI se transformou, a partir da liderança do general Emílio Garrastazu Médici no órgão, "em cabeça de uma ampla rede de espionagem" (FICO, 2004, p. 36), permanecendo com tal status ao longo dos anos porvindouros.

A estrutura organizacional do SNI previa uma chefia, com uma agência central no Distrito Federal e agências regionais, como a do Rio Grande do Sul, sediada em Porto Alegre. O chefe do SNI, civil ou militar, teria sua nomeação sujeita à aprovação prévia do Senado Federal, e usufruiria das honras e prerrogativas de ministro de Estado. Os funcionários dividiamse, entre outras categorias, em especialistas em movimento sindical, especialistas em movimento estudantil e especialistas em movimentos da Igreja (KORNIS, 2009).

O SNI acompanhou o regime militar e passou a sofrer alterações quando do processo de abertura política iniciado em fins da década de 1970. Foi necessário, ao longo das promessas de mudança, também repensar a atuação e os poderes dos quais estava investido o sistema. Para a redemocratização, o órgão federal de informações deveria perder muito de sua estrutura e poder, que haviam servido ao autoritarismo ditatorial (KORNIS, 2009). Dessa forma, para a passagem ao regime democrático, reformular o SNI constituia-se em um dos principais pontos da agenda política, não contemplado no governo Figueiredo, permanecendo como tarefa à administração da Nova República, que o extinguiria apenas em $1990^{5}$.

Em fevereiro de 1979, os eventos ocorridos em Passo Fundo foram comunicados ao órgão federal, que produziu informes investigativos e de apuração dos fatos nos dias que seguiram ao assassinato de Clodoaldo Teixeira. Acerca da questão, alguns documentos confidenciais foram gerados pelo órgão, sobre os quais deterse-á à análise de seus elementos constitutivos e informacionais. A partir dessa documentação, podemos inferir acerca das investigações operadas pelos agentes do SNI em Passo Fundo, buscando compreender como se estruturou o caso para as autoridades militares daquele momento.

Na versão recolhida pelos agentes do SNI, então repassada pelo Comandante da Brigada Militar em Passo Fundo, o tenente-coronel José Ângelo Lucas Dutra, Clodoaldo Teixeira não estava sozinho quando empreendeu fuga da patrulha, pois essa tentava, naquele dia, "interceptar motoqueiros que estariam transitando com excesso de velocidade" (BRASIL, 1979). Na versão do militar, publicada pelo Jornal do Brasil, Clodoaldo era um infrator e colocava a vida de outros em risco no dia em que foi assassinado. Negando a ocorrência da perseguição, o tenente-coronel afirmava que "os policiais desferiram apenas um disparo, para intimidá-los, mas, lamentavelmente, o tiro, acidentalmente, atingiu o rapaz de nome Clodoaldo Teixeira" (CABO..., 1979, p. 20).

De acordo com a documentação do SNI, na noite em que ocorreu o assassinato, após as 23h, a população jovem da cidade de Passo Fundo saiu às ruas em passeata, portando frases de contestação à atuação dos policiais da BM. A movimentação continuou no dia seguinte, durante e após o enterro de Clodoaldo. As motocicletas marcaram a presença nas manifestações de solidariedade ao jovem assassinado, resultando em grande mobilização dificil de ser contida pela polícia citadina. Naqueles dias, a grande 
mobilização resultou em quebra-quebras, tumultos e, inclusive, na queima de uma viatura policial (ALMEIDA, 2006).

Os manifestantes, que somariam algo em torno de três mil pessoas, dirigiram-se, armados com paus e pedras, para o centro da cidade, na Praça Marechal Floriano, área cercada pela BM, em função de ser o principal ponto de encontro da juventude do periodo. No centro, os militares destacados foram repelidos pela população mobilizada, tendo que buscar refúgio no Quartel do Comando de Policiamento da Área-3 (CPA-3), localizado em frente à antiga Prefeitura.

A movimentação dos manifestantes, entretanto, não cessou. Seguindo em direção ao CPA-3, a multidão cobrava a punição do assassino de Clodoaldo, que, a princípio, estava aquartelado naquela instalação. A tentativa de invasão do quartel não surtiu efeito, mas provocou a reação dos militares, que atiraram contra os manifestantes, matando Adão Faustino, operário de 19 anos, e deixando feridos outros com gravidade, como Pedro Carlos Santos, 24 anos, e Joceli Joaquim Macedo, 17 anos. Macedo viria a falecer dias depois, em função dos ferimentos (MENOR..., 1979, p. 20).

A instabilidade observada em Passo Fundo após a ação dos manifestantes em geral e da morte de mais dois jovens na sequência só fez arrefecer a partir da intervenção do Exército Federal, por meio do $3{ }^{\circ}$ Regimento de Cavalaria do município, comandado pelo Major Isauro Corrêa, obrigando os manifestantes a se dispersarem (BRASIL, 1979, p. 1).

A descrição do desenvolvimento das manifestações nas ruas de Passo Fundo advinha dos informes prestados pela Brigada Militar, de acordo com a documentação do SNI. Porém, percebe-se que, ao longo da constituição desses relatórios confidenciais, novos elementos vão sendo incorporados, externos ao contexto passo-fundense, como as repercussões daquela "perturbação da ordem" com a intervenção do Exército federal e as decisões tomadas pelo governo estadual no que tangia à segurança pública e ao comando da BM em Passo Fundo.
Os clamores e a pressão social sobre a situação tornaram-se questão de segurança pública em Passo Fundo. A situação exigiu providências por parte das autoridades militares, que consultaram - Secretário da Segurança Pública, Rubem Moura Jardim e o então governador, Sinval Guazzelli, decidindo pela necessidade da punição dos envolvidos. Na mesma reunião, decidiu-se também pela substituição do comandante da Brigada Militar, José Ângelo Lucas Dutra, medidas tomadas como profícuas.

O cabo José Valmor da Silva foi indiciado por homicídio qualificado, na condição de autor do crime, bem como Clóvis Amaral Raiter e Jacinto Xavier Chaves, na condição de coautores, pelo Promotor Público Benedicto Hespanha. Segundo o SNI, "a calma voltou a reinar, paulatinamente, em Passo Fundo", após a efetivação das decisões (BRASIL, 1979, p. 2-3).

A mudança no comando da BM também se constituía em uma ação em prol de acalmar os ânimos locais, tendo em vista que a posição defendida pelo tenente-coronel Lucas Dutra não reconhecia a morte de Clodoaldo como um assassinato, mas sim como um acidente, na tentativa de inocentar seus subordinados.

A questão, entretanto, não estava solucionada. A indignação pelos assassinatos cometidos pela polícia naquele curto interregno de tempo, mantinha a população em constante sobreaviso, embora as autoridades se mobilizassem em movimento contrário e a favor da desarticulação de movimentações envolvendo os jovens, sobretudo os motociclistas.

No dia 11 de fevereiro, quando se completava uma semana do assassinato de Clodoaldo, uma passeata de motociclistas estava prevista, em protesto às ações policiais dos dias anteriores. Contudo, ainda na noite do dia 9, o Moto Clube de Passo Fundo e o Comando da Brigada Militar se reuniram. E, chegando a um acordo, suspendeu-se o evento (MOTOCICLISTAS..., 1979, p. 8). Por iniciativa da BM, a familia da vitima foi instada a alterar o local da missa em homenagem à Clodoaldo, de um local mais centralizado - a Paróquia Santa Terezinha - para 
os subúrbios da cidade - a Capela Santo Antônio (MOTOCICLISTAS..., 1979, p. 8).

Entretanto, o cancelamento da passeata não foi decisão unânime, tampouco apoiada pelos elementos motociclistas de fora do Moto Clube. Orlando Riggon, motociclista de 20 anos, em entrevista ao Jornal do Brasil, assegurava que o cancelamento das passeatas na ocasião se dava para

[...] evitar mais tumultos e mortes, pois estamos saturados de tantos conflitos [...] várias vezes os PMs ameaçaram motociclistas com revólveres e somos alvo de constantes provocações. Eles nunca nos deixam tranquilos, quando nos atacam para pedir documentos quase sempre nos agridem moral ou corporalmente. O caso de Clodoaldo foi a gota d'água, o estopim para que a guerra fosse deflagrada e agora eles que arquem com as consequências. [...] (MOTOCICLISTAS..., 1979, p. 8).

Ainda conforme o relato de Riggon

Todo o pais sofre arbitrariedades semelhantes e, de repente, Passo Fundo se transformou num exemplo para outras cidades. Dezenas de motociclistas de Santa Catarina, Paraná e São Paulo estão chegando aqui para participar das manifestações. Defendendo que devemos continuar lutando para que tal tipo de coisa não se repita (MOTOCICLISTAS..., 1979, p. 8).

O depoimento de Orlando revela que, a seu ver, os motociclistas não eram bem vistos pela polícia militar passo-fundense do periodo e que a reação organizada e contundente desse grupo pode ter encontrado na morte um companheiro o caminho para o protesto, não só por Clodoaldo, mas pela repressão do regime e suas "arbitrariedades". Da mesma forma, denota também que a organização dos motociclistas foi para além de Passo Fundo e região, concitando e reunindo motociclistas descontentes do Sul do Brasil.

A questão da autoria do crime que vitimou Clodoaldo, imputada ao cabo Valmor e aos policiais envolvidos, seguiu para a Justiça Militar, constando também na documentação do SNI, que encerrou o acompanhamento do caso antes da decisão acerca da pena a ser cumprida pelos culpados. Ante à acusação, os militares alegaram que o tiro teria sido disparado contra Clodoaldo de maneira acidental, devido a um solavanco da viatura, durante a perseguição (PM'S..., 1979, p. 21), versão desacreditada com provas pela defesa, representada pelo advogado Irineu Gehlen.

Ainda naquele mês, o falecimento de Joceli Joaquim Macedo, filho do militar reformado Joaquim Macedo, em 19 de fevereiro, não permitiu que a questão fosse esquecida, causando mais uma vez revolta na cidade, em função da indisposição de médicos em realizar a autópsia no corpo do jovem, por temor de represálias, algo já ocorrido no caso Clodoaldo dias antes, que só teve o corpo analisado perante decisão judicial (MENOR..., 1979, p. 21).

De acordo com o SNI, o enterro de Joceli Macedo foi realizado no dia 22 daquele mês e, segundo os agentes,

[...] transcorreu sem nenhuma alteração e foi acompanhado por cerca de 500 pessoas, que se deslocaram em dois ônibus, 180 automóveis e 30 motos, aproximadamente. O trajeto até o Cemitério da Vila Petrópolis durou cerca de 45 minutos e nas ruas não havia policiamento reforçado, apenas algumas duplas de policiais militares, localizadas nos postos de costume (BRASIL, 1979, p. 1).

A descrição do enterro pelo órgão federal subsidia o controle aparente da situação pelas autoridades militares após o destacamento do Exército para o tratamento da questão, para controlar aquela "perturbação". Contudo, o relato assinala que, mesmo com a redução numérica dos envolvidos no cortejo fúnebre do corpo de Macedo, em relação aos atos relativos às despedidas póstumas atribuidas a Teixeira, grande comoção e participação de motociclistas se mantinha, ainda que, possivelmente, em protesto velado. Em realidade, este é o único trecho dos processos que faz referência à presença de motociclistas nos protestos. A investigação sobre os sujeitos envolvidos naqueles acontecimentos possuia um outro foco, que não os "motoqueiros".

Como já afirmamos anteriormente, os agentes do SNI mantiveram estreita vigilância quanto a estes episódios de violência e contestação que 
ocorreram em Passo Fundo naqueles dias de fevereiro. Em especifico, houve o esforço de se identificar, antes dos criminosos responsáveis pelos assassinatos dos jovens, a busca pela apuração dos participantes dos protestos contra a impunidade dos assassinos. Sob a pecha de "agitadores", membros da sociedade civil eram assim rotulados, considerando eventual ou concreta oposição política ao regime como um todo ou em atos especificos.

\section{Os agitadores: onde estão os "motoqueiros"?}

Os arquivos do SNI acerca da "perturbação pública", apesar de encerrarem a questão trazendo poucas informações acerca das resoluções empregadas pelo regime sobre as manifestações em torno do caso, denotam grande preocupação com os considerados "agitadores" do periodo. Nota-se que, aos olhos da vigilância do órgão federal, esses cidadãos em geral, já possuiam registros antecedentes de investigações no $\mathrm{SNI}$, devido a seus posicionamentos públicos contrários ao conceito de ordem pregado pelo regime. Enquadram-se nessa categoria, especialmente, jornalistas e políticos, bem como lideranças de movimentos autônomos e membros da sociedade civil em evidência.

Sobre os "agitadores da revolta", o SNI comprovou sua função de fiscalização e investigação ao listar aqueles que apareciam, durante o conturbado período, como as vozes de incitação e de contestação ao regime. Os "agitadores" da opinião pública em Passo Fundo seriam, segundo o órgão, Hélio Freitag, Argeu Rigo Santarém e Ivaldino Tasca, jornalistas, Ulisses Vieira Camargo e Ivo Pacheco, vereadores pelo Movimento Democrático Brasileiro (MDB), e Alberti dos Santos, vereador pela Aliança Renovadora Nacional (ARENA). Posteriormente, acrescentou-se à documentação o nome de Edu Pimentel, professor universitário.

Para cada elemento considerado "agitador", uma extensa ficha de manifestações, orais ou escritas, bem como denúncias, eram trazidas à tona a partir das documentações precedentes do órgão federal de informação. Com exceção de Alberti dos Santos, que estava filiado ao partido de sustentação do regime, e Edu Pimentel, os demais contavam com ampla descrição de observação desde os anos iniciais da ditadura.

A menção aos referidos faz com que o relatório retome todas as particularidades sobre eles, mesmo estas tendo pouco ou nada a ver com as manifestações de fevereiro de 1979. A exemplo disso, a descrição atribuída a Argeu Rigo Santarém, por exemplo, informa ao início dados de filiação e naturalidade, apresentando dois números de relatórios anteriores com antecedentes relacionados com à "subversão". Descobre-se pelo documento que, em março de 1977, Santarém publicou artigos, em coluna denominada "O Foca", no jornal O Nacional, contendo pretensos "ataques violentos às ações do Governo Federal", em textos que frequentemente satirizavam o governo estabelecido.

Ainda em março de 1977. Santarém, na condição de vereador, proferiria discurso em oposição a atos da ditadura, como a manutenção do Ato Institucional $n^{\circ} 5$, o Al-5, que afetava a liberdade de expressão e determinava outras proibições. Conforme o mesmo documento, "pelo passado do nominado, por sua facilidade de penetração e doutrinação junto ao povo, com sua coluna jornalistica e, principalmente, por sua atuação como vereador em Passo Fundo/ RS", Santarém é apresentado como "pessoa de grande periculosidade, particularmente, por sua pregação de agitador" (BRASIL, 1979, p. 7).

Apesar da reafirmação dos antecedentes de Santarém, sua participação efetiva nos protestos não foi apurada pelo órgão de inteligência. Santarém havia, nos dias que seguiram à morte de Clodoaldo Teixeira, se contraposto à versão que passou a circular como oficial, propagada pela BM, desautorizando-a como órgão passivel de esclarecer o que havia ocorrido na noite do dia 05 de fevereiro, pois a polícia negava a versão de testemunhas oculares sobre fatos ocorridos no centro da cidade (CABO..., 1979, p. 20).

Ivo Pacheco e Ulisses Vieira Camargo, vereadores do MDB, a exemplo de Santarém, 
também foram enquadrados como "agitadores". Ivo Pacheco era vice-líder da bancada do MDB municipal e em sua ficha pesavam alguns de seus atos de anos anteriores, como a recusa em participar de cerimônia de comemoração da "Revolução de 1964" na Câmara de Vereadores de Passo Fundo, em 31 de março de 1976, e seu posicionamento contra a cassação de políticos de seu partido naquela mesma década. Ademais, os informantes do SNI demonstraram sua capacidade de inserção em movimentos de oposição ilegais, caso do grupo Tendência Socialista, sobre o qual era de notório conhecimento dos militares a integração de Pacheco (BRASIL, 1978).

Sobre Camargo, o SNI apurou poucos detalhes além de sua atuação na vereança, salientando, porém, uma suspeita do envolvimento do político em "uma negociata ilícita de venda de automóveis" (BRASIL, 1979, p. 3-4), demonstrando que a vigilância dos oposicionistas do regime estendia-se para além dos órgãos de mídia e da Câmara de Vereadores.

No que se refere a Hélio Freitag e Ivaldino Tasca, figurava o interesse nos conteúdos de suas manifestações jornalísticas, do primeiro, no Diário da Manhã, e, do segundo, na Rádio Passo Fundo e em O Nacional, órgãos da imprensa de acirrada concorrência entre si. Ambos os jornalistas supracitados eram arrolados no processo também sem a apresentação de uma justificativa clara de suas ações durante as manifestações. O processo considerava a opinião do prefeito do municipio entre 1972 e 1977, o tenente-coronel Edu Villa de Azambuja, que delegava a eles a condição de "extremistas ou adeptos da situação anterior a 1964" (BRASIL, 1979, p. 3).

Hélio Freitag já era previamente fichado no SNI por uma série de três reportagens de sua autoria e de Argeu Santarém, publicadas no Diário da Manhã, sobre arbitrariedades praticadas por militares contra invasores da Reserva Florestal da Companhia de Energia Elétrica (CEE), em 1973. Ivaldino Tasca, porém, possuía uma ficha mais extensa nos registros do órgão de vigilância: partícipe do Movimento Estudantil, em outubro de 1968, havia tomado parte no XXX Congresso da União Nacional dos Estudantes (UNE), em Ibiúna/SP, quando foi preso e enquadrado na Lei de Segurança Nacional (LSN), em vigor desde março de 1967, devido à vigente clandestinidade da agremiação estudantil (FRANDOLOSO, 2019).

Por toda a década seguinte, a vigilância se manteve, de forma a reconhecer em Tasca um "elemento subversivo", devido ao periodo em que esteve à frente ao Diretório Acadêmico João Carlos Machado, da Faculdade de Direito da Universidade de Passo Fundo, e por seus comentários na coluna "Informes Especiais", em O Nacional, muitos deles transcritos pelas autoridades e anexados à ficha do processo, sobre temáticas como o Movimento Estudantil e o comunismo.

Junto à imprensa local, destaca-se também a presença do jornalista passo-fundense Tarso de Castro. Visado pelo regime por suas posições de contestação e trabalhos desenvolvidos em periódicos, como O Pasquim e Última Hora, Castro esteve de passagem por curto período em Passo Fundo, desenvolvendo funções editoriais no jornal O Nacional, de propriedade de seu pai, Múcio de Castro (ALMEIDA, 2006, p. 287).

Sob sua direção, a manchete de O Nacional, "Tiro nas costas", deu início à cobertura jornalística do periódico à questão, que se tornou central durante todo o mês, em função dos desdobramentos que se estenderam para além da morte de Clodoaldo. Tarso conduziu as quatro matérias principais sobre a questão que envolveu a revolta e organização da população em protesto (CASTRO FILHO, 2004 apud ALMEIDA, 2007, p. 287).

Batistella e Ribas (2010) enfatizam que Tarso se inspirava no jornalismo desenvolvido no centro do país, comprometendo-se ele também, como já o fazia, em mostrar abusos praticados pelas autoridades militares. Ao tempo dos fatos ocorridos em Passo Fundo, Tarso já havia sido preso algumas vezes pelo regime. De antemão, Tarso de Castro não aparece como um dos "agitadores" da perturbação em Passo Fundo. Torna-se notório que o jornalista não esteja arrolado em primeira mão na lista, já que foi o redator do jornal que deu a maior cobertura ao caso, acerca do qual escreveu editoriais tomando parte do ocorrido e 
condenando a ação policial. Tarso foi citado apenas duas semanas após o fim dos protestos (BRASIL, 1979). A referência tardia pode estar atrelada ao fato de as reportagens que dirigira terem sido publicadas ao longo daqueles dias de tensão.

A participação do jornalista nas manifestações se fez notória, em claro desafio às autoridades militares responsáveis pela "manutenção da ordem" em Passo Fundo. Segundo Ivaldino Tasca, colega de redação de Tarso de Castro em $O$ Nacional, "ele colocou a vida em risco e esteve perto de aumentar o caos local, ao provocar um acuado soldado da Brigada Militar que estava com arma em punho" (TASCA, 2010, p. 128). Desse modo, Tarso de Castro foi descrito como "agitador", de acordo com a documentação, mais em razão de sua participação nos "protestos e balbúrdias na cidade" (BRASIL, 1979) do que propriamente por sua redação de denúncia no jornal, que sequer foi mencionada nos processos do SNI referentes a esse caso.

Por fim, dos agitadores citados, estavam elencados Alberti dos Santos, vereador pela ARENA, sobre o qual o SNI reconheceu não haver antecedentes, ou qualquer forma de contestação ao regime, mas que, na ocasião dos protestos, fora um de seus ativistas. O professor universitário da Faculdade de Economia da UPF, Edu Pimentel, que, em princípio também aparecia pela primeira vez nos registros do SNI, mas taxado apenas como comunista e líder do ataque ao CPA-3 (BRASIL, 1979), também foi sinalizado na condição de agitador.

Contudo, a falta de informações no caso de Edu Pimentel, ao que tudo indica, tratou-se de um erro de levantamento dos agentes, que não o identificaram por seu nome completo e, portanto, não o relacionaram com Edu João Pimentel, fichado ainda no início da década de 1970 como estudante de Economia da Universidade Federal do Rio Grande do Sul, quando havia pleiteado, sem sucesso, a concessão de uma bolsa de estudos em Economia Social na Universidade Patrice Lumumba, em Moscou, na União Soviética (BRASIL, 1971, p. 1-4).

O SNI, dessa forma, mostrou-se atuante nos eventos de revolta e "perturbação" em
Passo Fundo, no sentido de coletar e conjugar informações de inteligência, não se mantendo à parte dos acontecimentos. A agência revelou, na ocasião, que Passo Fundo concentrava um grupo de pessoas que contestavam e faziam oposição veemente ao regime militar e que, por isso, conservavam uma extensa ficha de observação do órgão federal de investigação. Assim, não se encontravam afinados com o discurso próprio da ditadura, sendo considerados inimigos da ordem ou subversivos, não apenas naquela ocasião.

A vigilância do SNI recaiu, nesse episódio de protestos e confrontos entre os manifestantes e a polícia militar, não sobre aqueles que, em movimento de massa - como foi o caso dos motociclistas - foram às ruas em prol da justiça e esclarecimento dos crimes cometidos pela BM. Mas sobre os que possuiam destaque nos meios de comunicação, na educação e na política, os que eram evidenciados em canais de difusão de opinião. Estes se constituiam, na visão dos militares detentores do poder, como ideologicamente mais contestadores do regime instituído do que a própria "perturbação da ordem pública".

\section{Considerações finais}

O assassinato de Clodoaldo gerou revolta de motoqueiros e da população contra a Brigada Militar, cujas lideranças se negavam a punir os responsáveis. Os protestos iniciaram pedindo justiça, por meio da condenação do cabo Valmor, autor dos disparos, e se propagaram pela cidade por mais três dias, envolvendo cerca de dez mil pessoas. Terminaram como um ato de resistência frente ao desgaste da ditadura militar, onde o sentimento foi condensado na indignação advinda dos assassinatos promovidos por policiais militares em fevereiro de 1979, tomando proporções mais destacadas no panorama de poucas liberdades individuais e coletivas.

Em que pese a grande participação de motociclistas nas manifestações, fica evidente na documentação produzida pelo SNI que a vigilância sobre os participantes da revolta se processou sobre aqueles que, na avaliação das autoridades locais e do próprio órgão de 
inteligência, haviam sido promotores daquela contestação às ações e a participação da Brigada Militar, nos ataques que resultaram no falecimento de Clodoaldo Teixeira e na posterior repressão sobre as manifestações.

Em meio a esse contexto, a presença dos chamados "agitadores", vozes ativas contra o regime ditatorial, fez com que os militares, por meio de seu principal órgão de espionagem, observassem com atenção os desdobramentos. $\mathrm{Na}$ documentação produzida pelo SNI, paradoxalmente, os "motoqueiros" e sua revolta, recordados na memória passo-fundense em um episódio de contestação à ditadura, pouco aparecem e revelam nuances da visão institucional, do governo estadual e federal, sobre aquela sequência de eventos, viés ainda pouco explorado pela historiografia local/regional, o qual ainda é fértil para o desenvolvimento de outras análises, que aqui não se intentou esgotar.

Naquele ano, a Lei de Anistia, aprovada em agosto pelo ditador João Baptista Figueiredo, foi um dos primeiros sinais de que o regime estava terminando. O jogo do poder já se reorganizava em torno de novos partidos, que substituiriam ARENA e MDB ao final de 1979. O espírito de contestação se fortaleceu nos atos de protesto. Os então habitantes de Passo Fundo, dotados de indignação, tornaram a morte de Clodoaldo, um símbolo para as transformações sociais que se almejavam no Brasil.

\section{Referências}

ALMEIDA, José Ernani de. Denuncismo \& Censura nos meios de comunicação de Passo Fundo - 1964/1978. Passo Fundo: Méritos, 2007.

BATISTELLA, Alessandro, RIBAS, João Vicente. Tarso de Castro: O passofundense menos passofundense do Brasil. In: GAGLIETI, Mauro; CARMO, Aline do; SCHAEFFER, Olmiro (org.). Rato de redação: homenagem a Tarso de Castro, um jornalista brasileiro. Passo Fundo: IMED, 2010. p. 105-114

BRASIL. Serviço Nacional de Informações. Agência de Porto Alegre. Perturbação da ordem pública em Passo Fundo/RS. Porto Alegre, 14 fev. 1979. Arquivo Nacional. Fundo Serviço Nacional de Informações. Disponível em: http://sian.an.gov.br. Acesso em: 01 fev. 2019.
BRASIL. Serviço Nacional de Informações. Agência de Porto Alegre. Perturbação da ordem pública em Passo Fundo/RS. Porto Alegre, 23 fev. 1979. Arquivo Nacional. Fundo Serviço Nacional de Informações. Disponível em: http://sian.an.gov.br. Acesso em: 01 fev. 2019.

BRASIL. Serviço Nacional de Informações. Agência de Porto Alegre. Incidente entre populares e policiais em Passo Fundo/RS. Porto Alegre, 23 fev. 1979. Arquivo Nacional. Fundo Serviço Nacional de Informações. Disponivel em: http://sian.an.gov.br. Acesso em: 01 fev. 2019.

BRASIL. Serviço Nacional de Informações. Agência de Porto Alegre. Incidente entre populares e policiais em Passo Fundo/RS. Porto Alegre, 16 fev. 1979. Arquivo Nacional. Fundo Serviço Nacional de Informações. Disponivel em: http://sian.an.gov.br. Acesso em: 01 fev. 2019.

BRASIL. Serviço Nacional de Informações. Agência de Porto Alegre. Lideres da perturbação à ordem pública - Passo Fundo/RS. Porto Alegre, 23 fev. 1979. Arquivo Nacional. Fundo Serviço Nacional de Informações. Disponivel em: http://sian.an.gov.br. Acesso em: 01 fev. 2019.

BRASIL. Serviço Nacional de Informações. Agência de Porto Alegre. Infiltração comunista no Brasil. Porto Alegre, 15 mar. 1971, p. 01-04. Arquivo Nacional. Fundo Serviço Nacional de Informações. Disponivel em: http://sian.an.gov.br. Acesso em: 01 fev. 2019.

BRASIL. Serviço Nacional de Informações. Agência de Porto Alegre. Tendência Socialista/MDB/RS. Porto Alegre, 25 out. 1978. Arquivo Nacional. Fundo Serviço Nacional de Informações. Disponivel em: http://sian. an.gov.br. Acesso em: 01 fev. 2019

CABO da PM mata jovem em Passo Fundo e causa conflito. Jornal do Brasil, Rio de Janeiro, 07 fev. 1979, p. 20. Disponivel em: http://memoria.bn.br/docreader/030015_09/194011. Acesso em: 21 fev. 2019.

CAMARGO, Ana Maria de Almeida. A Imprensa Periódica como Fonte para a História do Brasil. In: SIMPÓSIO NACIONAL DOS PROFESSORES UNIVERSITÁRIOS DE HISTÓRIA, 5., 1971. Anais do [...] São Paulo: Revista de História, 1971.

COMOÇÃO semelhante na cidade somente em 1954 quando morreu Getúlio Vargas. O Nacional. Passo Fundo, 07 fev. 1979, p. 2.

DE LUCA, Tânia Regina. Fontes Impressas: História dos, nos e por meio dos periódicos. In: PINSKY, Carla Bassanesi (org.). Fontes Históricas. São Paulo: Contexto, 2008

DELGADO, Lucilia de Almeida Neves; FERREIRA, Marieta de Moraes (org.). História do Tempo Presente. Rio de Janeiro: FGV, 2014. DOI: https://doi.org/10.20949/ rhhj.v2i4.90.

FAUSTO, Boris. História Concisa do Brasil. São Paulo: Edusp, 2015

FICO, Carlos. História do Brasil Contemporâneo: da Morte de Vargas aos Dias Atuais. São Paulo: Contexto, 2016. 
FICO, Carlos. Versões e Controvérsias sobre 1964 e a Ditadura Militar. Revista Brasileira de História, São Paulo, v. 24, n. 47, p. 29-60, 2004. DOI: https://doi. org/10.1590/S0102-01882004000100003.

FRANDOLOSO, Hérica de Matos. "Não nos calemos; Ergamo-nos unidos!": o Movimento Estudantil de Passo Fundo em 1968. In: VANIN, Alex Antônio; CARVALHO, Djiovan Vinicius. Passo Fundo: Estudos Históricos. Passo Fundo: Acervus, 2019. v. 1. p. 365-400.

KORNIS, Mônica. Serviço Nacional de Informações. In: ABREU, Alzira Alves de et al. (coord.). Dicionário Histórico-Biográfico Brasileiro - Pós-1930. Rio de Janeiro: CPDOC, 2009.

MELO, Demian Bezerra de. Ditadura "Civil-Militar"? Controvérsias historiográficas sobre o processo político brasileiro no pós-1964 e os desafios do tempo presente. Revista Espaço Plural, [s. l.], v. 13, n. 27, p. 39-53, 2012.

MENOR baleado nas costas pela polícia gaúcha morre após 15 dias no hospital. Jornal do Brasil. Rio de Janeiro, 22 fev. 1979, p. 20. Disponivel em: http:// memoria.bn.br/docreader/ 030015_09/194771. Acesso em: 21 fev. 2019

MOTOCICLISTAS cancelam protesto contra a Brigada Militar em Passo Fundo. Jornal do Brasil. Rio de Janeiro, 11 fev. 1979, p. 08. Disponivel em: http://memoria.bn.br/ docreader/030015_09/194173. Acesso em: 21 fev. 2019

PASSO Fundo 79: Um pesadelo? O Nacional. Passo Fundo, 31 dez. 1979, p. 1.

PMs gaúchos dizem como rapaz morreu. Jornal do Brasil. Rio de Janeiro, 18 abr. 1979, p. 21 Disponivel em: http://memoria.bn.br/docreader/030015_09/197623. Acesso em: 21 nov. 2018.

SALOMÃO, Elisabete Becker. Revolta dos Motoqueiros. In: ZANOTTO, Gizele (org.). Mapeamento do patrimônio imaterial de Passo Fundo. Passo Fundo: Projeto Passo Fundo, 2016. p. 89-91.

SANTARÉM, Argeu Rigo. A República dos Coqueiros: histórias e estórias do Passo Fundo. Não-Me-Toque: Gráfica Editora Santo Antônio, 1984.

SCHWARCZ, Lilia M.; STARLING, Heloisa. Brasil: Uma Biografia. São Paulo: Companhia das Letras, 2015

SKIDMORE, Thomas E. Brasil: De Getúlio Vargas a Castelo Branco (1930-1964). 7. ed. Rio de Janeiro: Paz e Terra, 2007

TASCA, Ivaldino. Cinco ou seis $\left({ }^{*} \#\right.$ * e algumas reflexões sobre Tarso. In: GAGLIETI, Mauro; CARMO, Aline do; SCHAEFFER, Olmiro (org.). Rato de redação: homenagem a Tarso de Castro, um jornalista brasileiro. Passo Fundo: IMED, 2010. p. 115-130.

TIRO nas costas. O Nacional. Passo Fundo, 06 fev. 1979, p. 1.

TOLEDO, Caio Navarro de. O golpe contra as reformas. Revista Brasileira de História, São Paulo, v. 24. n. 47, p. 13-28, 2004. DOI: https://doi.org/10.1590/ S0102-01882004000100002
VAINER, Bruno Zilberman. Breve Histórico acerca das Constituições do Brasil e do Controle de Constitucionalidade Brasileiro. Revista Brasileira de Direito Constitucional-RBDC, [s. l.], n. 16, p. 161-191, jul./dez. 2010.

VERSIANI, Maria Helena. A sociedade brasileira vive a democracia (1985-1987). In: DELGADO, Lucilia de Almeida Neves; FERREIRA, Marieta de Moraes (org.). História do Tempo Presente. Rio de Janeiro: FGV, 2014.

\section{Alex Antônio Vanin}

Mestrando em História pela Universidade de Passo Fundo (UPF, Passo Fundo, RS, Brasil).

\section{Roberto Biluczyk}

Mestrando em História pela Universidade de Passo Fundo (UPF, Passo Fundo, RS, Brasil).

\section{Endereço para correspondência}

Alex Antônio Vanin/ Roberto Biluczyk

Universidade de Passo Fundo

BR 285, km 292,7 - Campus I, Prédio B4

São José, 99052-900

Passo Fundo, RS, Brasil 